\title{
A Política Nacional de Plantas Medicinais e Fitoterápicos e sua relação com a repartição de benefícios
}

The National Policy of Medicinal and Phytotherapic plants and their relationship with the benefit sharing

\section{Gustavo Borja dos Reis}

Autor

gstv.reis1@gmail.com

Graduando em Ciências Biológicas da

PUC-Rio.

\section{Mariana Henriques Santana}

Autora

mar3santana@gmail.com

Graduanda em Ciências Biológicas da

PUC-Rio.

\section{João Roberto Lopes Pinto}

\section{Orientador \\ joaoroberto1967@gmail.com}

Doutor em Ciência Política pela IUPERJ, professor no Departamento de Estudos Políticos da UNIRIO, professor no Departamento de Ciências Sociais da PUC-Rio, coordenador do Instituto Mais Democracia.

\section{Resumo}

A repartição de benefícios resultante do acesso ao patrimônio genético e do conhecimento tradicional associado, para a elaboração de novos produtos, em alguns casos, deixa de ser aplicada por empresas que gozam desses recursos. Este estudo expõe a natural fragilidade brasileira no tema devido às características geográficas e biológicas, assim como estratégias usadas para ludibriar o sistema e isentar empresas das responsabilidades jurídicas.

Palavras-chave: comunidades tradicionais; conhecimento tradicional associado; repartição de benefícios; plantas medicinais.

\begin{abstract}
The benefits sharing resulting from the access of the genetic patrimony and the traditional knowledge associated, to develop new products, in some cases tend to not be applied for companies that takes part of this resources. This study exposes the brazilian natural weakness about the theme in function of the geographic and biological characteristics, and some strategies used to hoodwink the process and acquit the legal responsibilities.

Keywords: traditional communities; associated traditional knowledge; benefit sharing; medicinal plants.
\end{abstract}




\section{Introdução}

Este trabalho visa explorar com ênfase a questão da promoção do uso sustentável da biodiversidade e a repartição de benefícios, além de tratar da questão da divisão dos ganhos provenientes da exploração econômica de produto acabado ou material reprodutivo desenvolvido, oriundo de patrimônio genético ou conhecimento tradicional associado.

O artigo aborda a política e utiliza estudos de caso para indagar como são tratadas as questões referentes ao tema a partir do que é proposto na Política Nacional de Plantas Medicinais e Fitoterápicos, relacionando-a então, com o processo de repartição de benefícios atual. Em seguida, analisa-se a questão do direito e como isso é revertido aos detentores dos conhecimentos sobre os recursos utilizados. Por fim, conclui com o entendimento de que a problemática existente entre a Política Nacional de Plantas Medicinais e Fitoterápicos e a repartição de benefícios é extremamente complexa.

\section{Plantas medicinais e fitoterápicos}

Para iniciarmos o debate acerca da Política Nacional de Plantas Medicinais e Fitoterápicos, é necessário antes conceituar esses dois termos fundamentais para elaboração dessa política. A Organização Mundial da Saúde define planta medicinal como "todo e qualquer vegetal que possui, em um ou mais órgãos, substâncias que podem ser utilizadas com fins terapêuticos ou que sejam precursores de fármacos semissintéticos”, sendo essa a definição mais utilizada para diversos fins (OMS, 1979, e MS, 2003).

Já o termo fitoterápico é definido pela Secretaria de Vigilância Sanitária, em sua portaria $\mathrm{n}^{\mathrm{o}} 6$ de 31 de janeiro de 1995, como "todo medicamento tecnicamente obtido e elaborado, empregando-se exclusivamente matérias-primas vegetais com finalidade profilática, curativa ou para fins de diagnóstico, com benefício para o usuário. É caracterizado pelo conhecimento da eficácia e dos riscos do seu uso, assim como pela reprodutibilidade e constância de sua qualidade. É o produto final acabado, embalado e rotulado. Na sua preparação podem ser utilizados adjuvantes farmacêuticos permitidos na legislação vigente. Não podem estar incluídas substâncias ativas de outras origens, não sendo considerado produto fitoterápico quaisquer substâncias ativas, ainda que de origem vegetal, isoladas ou mesmo suas misturas". Neste último caso encontra-se o fitofármaco, que por definição "é a substância ativa, isolada de 
REIS, Gustavo Borja; SANTANA, Mariana Henriques; PINTO, João Roberto Lopes. A Política Nacional de Plantas Medicinais e Fitoterápicos e a sua relação com a repartição de benefícios.

matérias-primas vegetais ou mesmo, mistura de substâncias ativas de origem vegetal" (ANVISA, 2011).

A partir dessa conceituação, de um modo geral, a diferença entre os termos planta medicinal e fitoterápico reside basicamente na transformação da planta ou droga vegetal para formulações específicas, o que caracteriza um fitoterápico. Com relação aos usos, o Brasil tem uma rica história de uso das plantas medicinais construída com base na experiência e transmitida de forma oral (BRUNING et al., 2012). Largamente usada até meados do século XX, a fitoterapia entrou em declínio com a intensificação do uso dos medicamentos industrializados (BRUNING et al., 2012). Com o crescente desenvolvimento da química, houve então a substituição das plantas medicinais e da fitoterapia pelo uso de medicamentos sintéticos na segunda metade do século XX (YUNES et al., 2001; CECHINEL-FILHO et al., 2001).

Apesar da constatação do aumento da substituição da fitoterapia por medicamentos industrializados, a Organização Mundial da Saúde estima que $80 \%$ da população de países em desenvolvimento não tem acesso a eles, sendo as plantas medicinais os únicos recursos terapêuticos (JUNIOR et al., 2005). Além disso, nos países em desenvolvimento, bem como nos mais desenvolvidos, há um crescente apelo da mídia para o consumo de produtos à base de fontes naturais que aumentam a cada dia (FIGUEIREDO et al., 2014), mesmo que, no Brasil, a flora medicinal nativa seja utilizada com pouca ou nenhuma comprovação de suas propriedades terapêuticas.

Já em lugares como os Estados Unidos e na Europa, há um controle maior no que diz respeito ao registro e a comercialização de produtos obtidos de forma natural, incluindo os que são provenientes de plantas, visto que as normas de certificação e controle de qualidade são mais rígidas. Além disso, pesquisas revelaram que os EUA apresentaram uma porcentagem de utilização de plantas medicinais que cada vez mais vem crescendo. Comparando, por exemplo, os anos de 1990 e 1996, houve um aumento de 8,2\% na utilização de plantas medicinais pela população. O consumo europeu tem a Alemanha como um dos maiores consumidores de extratos vegetais (JUNIOR et al., 2005; FIGUEIREDO et al., 2014).

A partir desse contexto, é possível situar a formulação e a implementação da Política Nacional de Plantas Medicinais e de Fitoterápicos, assim como demonstrar a necessidade e a importância dessa política para o Brasil, visto que ela se baseia no reconhecimento do avanço na comprovação científica da eficácia e da segurança das plantas medicinais e dos medicamentos fitoterápicos. 


\section{Política Nacional de Plantas Medicinais e Fitoterápicos}

O programa de medicina tradicional, criado pela Organização Mundial da Saúde (OMS) no fim da década de 1970 e reforçado pela organização em 2002/2005, propõe o desenvolvimento de políticas públicas que auxiliem e promovam a integração da medicina tradicional nos sistemas de atenção à saúde dos 191 estados-membros. Ainda que a medicina esteja se modernizando no mundo, a OMS reconhece que grande parte da população global ainda depende da medicina tradicional para atenção primária à saúde - aproximadamente $80 \%$ da população de países desenvolvidos empregam métodos tradicionais nos cuidados básicos de saúde e $85 \%$ desses utilizam plantas, seja na forma natural ou em preparações (BRASIL, 2006).

No Brasil, o incremento terapêutico oferecido pelo Sistema Único de Saúde (SUS) aos usuários utilizando plantas medicinais se mostra uma importante estratégia na busca da melhoria na atenção básica de saúde (BRASIL, 2006).

A elaboração de uma política nacional que trata da utilização de plantas medicinais e fitoterápicos é resultado de uma luta anterior à criação do SUS, onde diversos pesquisadores, gestores e profissionais da área da saúde atuaram de forma fundamental (FIGUEIREDO et al., 2014). Essa implementação no campo da saúde pública representa um aumento na possibilidade de tratamentos para a população que busca o SUS e para os profissionais de saúde, além do resgate de práticas milenares, mesclando o conhecimento científico com o popular sobre doenças e formas de tratamento (FIGUEIREDO et al., 2014).

A Política Nacional de Plantas Medicinais e Fitoterápicos foi criada no ano de 2006, por meio do Decreto da Presidência da República ${ }^{\circ}$ 5.813, de 22 de junho. Dentre os objetivos específicos desta política está o uso sustentável da biodiversidade e a repartição de benefícios oriundos de plantas medicinais e dos conhecimentos tradicionais associados. Um dos direitos humanos fundamentais do homem está relacionado a garantia de um meio ambiente ecologicamente equilibrado para as presentes e futuras gerações, no entanto existe uma problemática que tange tal direito, relacionado ao uso dos recursos, visto que esses são consumidos de forma desenfreada sem qualquer cuidado. Ao passo que esses recursos são utilizados dessa forma, há a promoção da sustentabilidade no que diz respeito ao desenvolvimento das comunidades tradicionais, que poderia então, ser usado como molde pois essas detêm o conhecimento associado à biodiversidade, utilizando-a de modo sustentável, permitindo que não apenas os recursos, mas também todo ecossistema se mantenha, por minimizar os danos e respeitar a resiliência do ambiente. Dessa forma, as comunidades 
REIS, Gustavo Borja; SANTANA, Mariana Henriques; PINTO, João Roberto Lopes. A Política Nacional de Plantas Medicinais e Fitoterápicos e a sua relação com a repartição de benefícios.

tradicionais, por meio de seu conhecimento passado de geração em geração, merecem obter reconhecimento e que haja uma repartição de benefícios de maneira justa e correta, pois esses desempenham um papel fundamental na manutenção de um direito primordial que envolve o meio ambiente, o ser humano, o manejo de recursos naturais e o desenvolvimento sustentável.

De acordo com o Ministério do Meio Ambiente:

"A Repartição de Benefícios consiste na divisão dos benefícios provenientes da exploração econômica de produto acabado ou material reprodutivo desenvolvido a partir do acesso a patrimônio genético ou a conhecimento tradicional associado.” (MINISTÉRIO DO MEIO AMBIENTE)

O processo de repartição de benefícios possui dois principais: os usuários e os detentores do conhecimento tradicional. Os usuários são representados pelos geradores de produtos oriundos do conhecimento tradicional associado ou patrimônio genético; ou seja, pesquisadores de várias áreas de conhecimento e indústrias de diversos setores como a de cosméticos e fármacos. Já os detentores do conhecimento tradicional são compostos pelos fornecedores do conhecimento sobre o patrimônio genético, um bem de uso comum do povo, aplicado pelos usuários (MINISTÉRIO DO MEIO AMBIENTE - Brasil). De acordo com a Lei Nº 13.123, de 20 de maio de 2015, referente ao acesso ao patrimônio genético, sobre a proteção e o acesso ao conhecimento tradicional associado e sobre a repartição de benefícios para conservação e uso sustentável da biodiversidade, a repartição aos provedores do conhecimento pode ser monetária e não monetária. Nessa última modalidade, estão incluídos, de acordo com o Artigo 19 desta lei:

a) projetos para conservação ou uso sustentável de biodiversidade ou para proteção e manutenção de conhecimentos, inovações ou práticas de populações indígenas, de comunidades tradicionais ou de agricultores tradicionais, preferencialmente no local de ocorrência da espécie em condição in situ ou de obtenção da amostra quando não se puder especificar o local original;

b) transferência de tecnologias;

c) disponibilização em domínio público de produto, sem proteção por direito de propriedade intelectual ou restrição tecnológica;

d) licenciamento de produtos livre de ônus;

e) capacitação de recursos humanos em temas relacionados à conservação e uso sustentável do patrimônio genético ou do conhecimento tradicional associado; e

f) distribuição gratuita de produtos em programas de interesse social. (BRASIL. Lei nº 13.123, 2015) 
REIS, Gustavo Borja; SANTANA, Mariana Henriques; PINTO, João Roberto Lopes. A Política Nacional de Plantas Medicinais e Fitoterápicos e a sua relação com a repartição de benefícios.

A modalidade de repartição concedida aos provedores do conhecimento é definida por negociação entre os usuários e os fornecedores do conhecimento. Nesse encontro é considerado também o consentimento prévio informado obtido, importante para acessar o conhecimento tradicional, além de proteger e garantir a possível repartição de benefícios com os detentores do conhecimento (MINISTÉRIO DO MEIO AMBIENTE).

\section{A problemática}

O Brasil é o país que abriga grande parte da diversidade biológica existente no mundo, cerca de 15 a $20 \%$. Em relação à diversidade vegetal, detém aproximadamente $24 \%$ da biodiversidade, sendo essa categoria de organismo a matéria-prima para a fabricação de fitoterápicos e outros medicamentos (BRASIL, 2006).

O Brasil, juntamente com outras 188 nações, é signatário da Convenção sobre Diversidade Biológica (CDB). Trata-se de um acordo determinado pela Organização das Nações Unidas no intuito de conservar a biodiversidade, usar seus componentes de forma sustentável e repartir de maneira justa e equitativa os benefícios decorrentes da utilização dos recursos genéticos. Visando atingir tais objetivos, a CDB destaca a importância dos conhecimentos tradicionais gerados, praticados e compartilhados por membros de comunidades tradicionais, como indígenas e quilombolas, atribuindo aos membros signatários a responsabilidade de assegurar a essas comunidades detentoras de conhecimento o direito de decidirem sobre sua aplicação, além de conhecerem os benefícios gerados a partir deles, uma vez que esses saberes são de grande valia na confecção de novos produtos oriundos da flora, como medicamentos e fitoterápicos (BRASIL, 2006).

Porém, segundo Saccaro Júnior (2011), em decorrência da extensão territorial do Brasil, o trabalho realizado contra a biopirataria - utilização de materiais biológicos, genéticos e/ou dos conhecimentos tradicionais associados a esses não respeitando as normas sociais, ambientais e culturais em vigor, e ausência do consentimento prévio das partes interessadas (HATHAWAY, 2004) - e o acesso indevido a comunidades tradicionais detentoras de conhecimento é árduo. Dessa forma, a obtenção de informações referentes a plantas ou animais, sendo estas elaboradas e acumuladas durante várias gerações por comunidades tradicionais, se torna mais fácil.

\section{Casos que envolvem a repartição de benefícios}




\section{Produtores de óleo de buriti (Mauritia flexuosa L.) de Palmeira do Piauí}

O caso dos produtores de óleo de buriti de Palmeira do Piauí, apresentado no artigo de Matta (2010), é um caso que consiste na dificuldade da repartição de bens, pautada na Política Nacional de Plantas Medicinais e Fitoterápicos. O óleo de buriti, utilizado principalmente para fins medicinais, comestíveis e utilitários (LORENZ, 2010), marca de forma expressiva o modo de vida e a economia dos moradores de Palmeira do Piauí, e tornou-se o meio pelo qual ocorreu a relação dos produtores de Palmeira do Piauí com a empresa de cosméticos Natura (que tem uma plataforma de negócios, desde 2000, pautada no uso sustentável da biodiversidade, abarcando diversas parcerias com comunidades tradicionais e agricultores familiares). No caso de Palmeira do Piauí, o relacionamento ocorreu por conta do acesso ao óleo de buriti para bioprospecção e o desenvolvimento tecnológico. A problemática se deu quando a empresa adquiriu o óleo de buriti com um comerciante do município de Palmeira do Piaú, com finalidade de realizar o desenvolvimento de produtos. A partir desse momento, houve uma dificuldade na identificação do universo de produtores locais que deveriam ser envolvidos no processo de anuência e de negociação de benefícios.

O processo se iniciou em 2006, quando os colaboradores da empresa foram a Palmeira do Piauí para adequar o acesso ao óleo de buriti, na tentativa de identificar, por meio do comerciante local, quais foram os produtores que forneceram a amostra de óleo de buriti para bioprospecção e desenvolvimento tecnológico. No entanto, essa identificação foi falha, porque o mesmo não possuía registro. Em seguida, a empresa tentou outra abordagem, que consistiu em buscar com uma associação a formalização do acesso, mas também não deu certo, pois os maiores produtores não participavam desse processo. Houve ainda diversas reuniões com pessoas da comunidade que detinham esse conhecimento, na tentativa de se chegar a um consenso, mas os resultados não foram promissores, pois diversas pessoas que não participaram de fato do processo de produção queriam se beneficiar monetariamente. Dessa forma, não conseguindo chegar a um consenso, a empresa não considerava que estava cumprindo com as diretrizes da Convenção sobre Diversidade Biológica. Diante da falta de rastreabilidade dos provedores e detentores do conhecimento, e com a ausência de pessoa jurídica que representasse os produtores da região, foi consultado o Departamento do Patrimônio Genético (DPG/Ministério do Meio Ambiente) para dar prosseguimento ao caso, mas não houve consenso. 
REIS, Gustavo Borja; SANTANA, Mariana Henriques; PINTO, João Roberto Lopes. A Política Nacional de Plantas Medicinais e Fitoterápicos e a sua relação com a repartição de benefícios.

Após todas as tentativas, que incluíram diversas reuniões com pessoas da comunidade e de retornos da empresa com o objetivo de compreender a situação e definir uma nova estratégia de regulamentação do acesso ao patrimônio genético e ao conhecimento tradicional associado ao óleo de buriti, definiu-se que o benefício seria voltado para ações de conservação ambiental, fortalecimento da cadeia produtiva do buriti e valorização cultural dos produtores de óleo de buriti, uma vez que se constatou que o buriti era fundamental para o modo de vida e a economia local.

\section{Discussão}

O processo foi extremamente complexo, visto que teve como objetivo não apenas regularizar o acesso ao patrimônio genético e ao conhecimento tradicional associado, mas discutir e construir conjuntamente um caminho que fosse repercutir em ações positivas para os envolvidos. Nesse caso, os próprios produtores questionaram sobre os detentores do conhecimento que teriam o direito ao benefício. Embora se soubesse quem produzia o óleo, que em geral eram algumas mulheres, em nenhum momento houve manifestações visando identificar quais seriam os beneficiários do processo, visto que dificilmente haveria um consenso por se tratar de conhecimentos compartilhados localmente. Esse ponto deve ser abordado e observado de forma a receber certo destaque, pelo fato de que na maioria das comunidades tradicionais e produtores familiares esse fator se repete, pelo fato de que os conhecimentos muitas vezes, senão em sua maioria, são passados de geração em geração, sem que se saiba de fato quem foi o real detentor de tal técnica, manejo ou produção de matérias provenientes de recursos naturais.

A decisão da empresa se deu ao colher informações provenientes de pessoas envolvidas diretamente no processo e no contexto local, sendo este um ponto que deve ser levado em consideração na hora da repartição de benefícios, visto que são essas pessoas que possuem o conhecimento das práticas locais, da dinâmica social e da vivência com as partes integrantes da sociedade, ao contrário de relatores que chegam na comunidade para definir quais medidas serão tomadas. Em conversas como essa, que buscam informações relevantes que resultem em estratégias para acordos, é possível observar a necessidade da comunidade, quais são os fatores mais importantes e o que de fato deve ser feito. Nesse caso específico, durante a conversa com as pessoas da comunidade envolvidas no processo, foi possível identificar que há uma importância na circulação dos produtos de buriti, no reconhecimento e na valorização dos 
REIS, Gustavo Borja; SANTANA, Mariana Henriques; PINTO, João Roberto Lopes. A Política Nacional de Plantas Medicinais e Fitoterápicos e a sua relação com a repartição de benefícios.

produtores de buriti de Palmeira do Piauí para além das pessoas que se envolveram diretamente no processo e do próprio contexto local, o que foi fundamental para anuência e definição dos benefícios que seriam recebidos por parte da empresa.

Por fim, no caso em questão, foi formalizada a relação entre os produtores de óleo de buriti e a empresa de cosméticos por meio da linguagem do direito, ou seja, com ênfase na repartição de benefícios de um produto com propriedades medicinais e de sua acomodação considerável às condições e diferentes posições obtidas. Além disso, foi possível construir um caminho partindo da tentativa de aplicar uma lógica mercantil a um universo baseado em práticas das relações familiares, ao qual o longo processo de entendimentos forneceu base para efeitos que continuam a existir.

Além disso, nesse caso foi possível identificar que houve a repartição de benefícios com a participação da comunidade detentora do conhecimento, que, por sua vez, buscou a melhor maneira de retorno em conjunto com a empresa, atuando na tomada de decisão, participando ativamente das ações e debates, e visando prioritariamente os interesses da comunidade. No entanto, essa é uma realidade não muito frequente, visto que as empresas que atuam buscando matéria-prima da diversidade existente no território brasileiro, coletam informações de comunidade tradicionais - muitas vezes pouco instruídas -, utilizam essa ingenuidade para se aproveitarem do seu conhecimento com a finalidade de lucrar, comercializando os produtos que são provenientes dessas culturas, descumprindo as políticas, leis e decretos existentes que respaldam esses grupos, sem reconhecer que essas comunidades são detentoras desse saber tradicional e que merecem o devido retorno por compartilhar esses conhecimentos milenares passados de geração em geração.

Sendo assim, esse tema, que aborda a relação entre repartição de benefícios, comunidades tradicionais e empresas, é algo extremamente complexo e deve ser tratado de maneira única, levando em consideração cada caso de modo particular, por conta das singularidades que cada um possui. Todavia, o que se deve saber antes de qualquer análise de caso é que todas as partes envolvidas nesse processo devem ser beneficiadas, constituindo assim uma via de mão dupla. Qualquer ação contrária a essa premissa deve ser avaliada e julgada para que haja então uma compensação e punições rígidas, de modo a vir reparar as ações que o processo de apropriação de conhecimento venha gerar, favorecendo então os detentores de conhecimento, que na maioria dos casos são os prejudicados de diversas formas.

\section{Índios Ashaninkas e o murumuru (Astrocaryum murumuru Mart.) no estado do Acre}


O caso dos índios Ashaninkas do estado do Acre, descrito no capítulo de Tarrega \& Franco, presente no trabalho de Plaza \& Del Nero (2012), consiste na prática de acesso e uso indevido do conhecimento tradicional associado detido pelos índios Ashaninka sobre a palmeira murumuru, utilizada por esta comunidade no tratamento de feridas e coceiras, bem como alimento e como pintura corporal (BEZERRA, 2012).

A problemática transcorre da solicitação ao Instituto Nacional da Propriedade Industrial (INPI) de quatro patentes, todas da classe "invenção" (PI), referentes a produtos, categorizados como hidratante e sabonete, fabricados a partir do uso da gordura parcial ou totalmente saponificada dos frutos de murumuru. Posteriormente a solicitação, os quatro pedidos foram questionados.

Assim, por esse motivo:

Em agosto de 2007 o Ministério Público Federal, por meio da Procuradoria da República no Acre, propôs ação civil pública contra quatro pessoas jurídicas, a saber: Fábio Dias Fernandes - ME, Chemyunion Química LTDA, Natura Cosméticos S.A. e Instituto Nacional da Propriedade Industrial. (TARREGA; FRANCO, 2012, p.26-58)

Dessa forma, foi solicitada a anulação das patentes requisitadas pelas marcas ao INPI ou de produtos e patentes que vierem a ser fabricados com uso direto ou indireto do conhecimento da comunidade Ashaninka. Além disso, foi solicitada a condenação desses atores por danos morais à sociedade e à comunidade, cujo valor atribuído à condenação foi determinado pelo juiz e dividido entre a Associação e metade ao Fundo Federal de Direitos Difusos.

Ao INPI, o Ministério Público exigiu que fosse indicada a origem do conhecimento tradicional e a justa distribuição dos benefícios gerados pela formulação de produtos, desenhos industriais, marcas ou patentes em que foram utilizados conhecimentos tradicionais.

\section{Discussão}

Nesse caso é revelada a utilização de uma estratégia denominada sui generis - descrição de um caso ou evento que nunca foi visto ou registrado antes -, o que isentaria os solicitantes das patentes de comunicarem a utilização de conhecimento tradicional associado no processo.

Além da ausência do conhecimento sobre o direito à repartição de benefícios revertidos na modalidade monetária ou não monetária (referentes tanto à confecção de produtos ou 
REIS, Gustavo Borja; SANTANA, Mariana Henriques; PINTO, João Roberto Lopes. A Política Nacional de Plantas Medicinais e Fitoterápicos e a sua relação com a repartição de benefícios.

patentes formuladas a partir de conhecimentos tradicionais; quanto à dificuldade de fiscalização devido à grande extensão territorial do Brasil e sua grande biodiversidade), as comunidades tradicionais muitas vezes são ludibriadas por algumas empresas que lançam mão de estratégias como a do presente caso, que dificultam a identificação (feita pelos órgãos responsáveis pela concessão de patente) do envolvimento de conhecimento tradicionais na confecção de produtos, sejam eles medicinais, alimentícios ou cosméticos. Assim, por meio desse caso, é possível iniciar um pensamento sobre possíveis estratégias desenvolvidas ou passíveis de serem desenvolvidas que podem estar sendo aplicadas pelas empresas com intuito de burlar o sistema de solicitação de patentes, excluindo sua responsabilidade de repartir os benefícios oriundos do conhecimento tradicional com as comunidades detentoras desse conhecimento.

\section{Conclusão}

Este artigo buscou explorar um dos objetivos específicos da Política de Plantas Medicinais e Fitoterápicos referentes à repartição de benefícios decorrentes do acesso aos recursos genéticos de plantas medicinais e do conhecimento tradicional associado, além de tratar da questão da divisão dos benefícios provenientes da exploração econômica de produtos concluídos ou material reprodutivo desenvolvido.

É possível perceber, por meio dos casos aqui apresentados e das dificuldades expostas por autores aqui citados, que a repartição de benefícios entre as comunidades detentoras desse conhecimento e as empresas geradoras de produtos e requerentes de patentes oriundos do conhecimento tradicional sobre o patrimônio genético nacional revela que ainda há complicações impostas pela ausência de informação concedida às comunidades, além das estratégias utilizadas por algumas empresas na tentativa da não repartição dos benefícios com os detentores e fornecedores de conhecimento.

Assim, o que se espera com esse estudo é que seja debatida a conduta e a conscientização das empresas no momento de repartir com as comunidades os benefícios gerados pelo trabalho de ambos, no intuito de garantir formas mais abrangentes de divulgação para as comunidades tradicionais sobre seus direitos à repartição de benefícios relacionada ao conhecimento tradicional associado e alertá-las sobre as possíveis estratégias desenvolvidas pelas empresas para obter o conhecimento de maneira ilícita, privando-as assim, do direito de obter as devidas modalidades de repartição. 
REIS, Gustavo Borja; SANTANA, Mariana Henriques; PINTO, João Roberto Lopes. A Política Nacional de Plantas Medicinais e Fitoterápicos e a sua relação com a repartição de benefícios.

\section{Referências bibliográficas}

BEZERRA, Valeria Saldanha. Considerações Sobre a Palmeira Murumuruzeiro (Astrocaryum murumuru Mart.). Embrapa Amapá, 2012.

BRASIL. Agência Nacional de Vigilância Sanitária. Formulário de Fitoterápicos da Farmacopeia Brasileira. Brasília: ANVISA, 2011. Disponível em 〈www.anvisa.gov.br〉. Acesso em: 14 jun 2019.

BRASIL. Lei Federal no 13.123, de 20 de maio de 2015. Acesso ao patrimônio genético, sobre a proteção e o acesso ao conhecimento tradicional associado e sobre a repartição de benefícios para conservação e uso sustentável da biodiversidade. Disponível em:

http://www.planalto.gov.br/ccivil_03/_ato2015-2018/2015/lei/113123.htm. Acesso em: 26 jun 2019.

BRUNING, M. C. R.; MOSEGUI, G. B. G.; VIANA, C. M. M. A utilização da fitoterapia e de plantas medicinais em unidades básicas de saúde nos municípios de Cascavel e Foz do IguaçuParaná: a visão dos profissionais de saúde. Ciência e Saúde coletiva, v.17, n.10, p.2.675-2.685, 2012.

CHECHINEL FILHO, V.; YUNES, R. A. Estratégias para a obtenção de compostos farmacologicamente ativos a partir de plantas medicinais. Conceitos sobre modificação estrutural para otimização da atividade. Química Nova, v.21, n.1, 1998. Disponível em:<http://www.scielo.br>. Acesso em: 14 jun 2019.

FIGUEREDO, C. A.; GURGEL, I. G. D.; GURGEL JUNIOR, G. D. A Política Nacional de Plantas Medicinais e Fitoterápicos: construção, perspectivas e desafios. Physis: Revista de Saúde Coletiva, v.24, p.381-400, 2014.

HATHAWAY, David. A biopirataria no Brasil. In: Sob o Signo das Bios: Vozes Críticas da Sociedade Civil. Rio de Janeiro: E-papers Serviços Editoriais, 2004.

JUNIOR, V. F. V.; PINTO, A. C.; MACIEL, M. M. Plantas medicinais: cura segura. Química nova, v.28, n.3, p.519-28, 2005.

LORENZ, S. S. Laudo antropológico de acesso a componente do patrimônio genético e ao conhecimento tradicional associado ao óleo de buriti (Mauritia flexuosa L.), no município de Palmeira do Piauí. Natura, São Paulo, 2010. Acesso restrito.

MATTA, Priscila. Conhecimento tradicional, biodiversidade e repartição de benefícios: o caso dos produtores de óleo de buriti de Palmeira do Piauí. Campos-Revista de Antropologia, v.11, n.2, 2010 .

MINISTÉRIO DA SAÚDE. Secretaria de Ciência, Tecnologia e Insumos Estratégicos. Seminário Nacional de Plantas Medicinais, Fitoterápicos e Assistência Farmacêutica: preparatório à Conferência Nacional de Medicamentos e Assistência Farmacêutica. Brasília: Ministério da Saúde, 2003. Relatório Técnico, p.2011. 
REIS, Gustavo Borja; SANTANA, Mariana Henriques; PINTO, João Roberto Lopes. A Política Nacional de Plantas Medicinais e Fitoterápicos e a sua relação com a repartição de benefícios.

MINISTÉRIO DA SAÚDE. Secretaria de Ciência, Tecnologia e Insumos Estratégicos Departamento de Assistência Farmacêutica. Política Nacional de Plantas Medicinais e Fitoterápicos. Brasília: Ministério da Saúde, 2006.

MINISTÉRIO DO MEIO AMBIENTE. Repartição de Benefícios e Regularização. Disponível em: $\quad<$ http://www.mma.gov.br/patrimonio-genetico/reparticao-de-beneficios-eregularizacao.html>. Acesso em: 26 jun 2019.

ORGANIZAÇÃO MUNDIAL DE SAÚDE/UNICEF. Cuidados Primários de Saúde. Relatório da Conferência Internacional sobre Cuidados Primários da Saúde, Alma-Ata, URSS, 6 a 12 de setembro de 1978. Brasília: Ministério da Saúde, p.64, 1979.

TARREGA, M. C. V. B.; FRANCO, R. D. Propriedade intelectual de biotecnologia e os conhecimentos tradicionais associados: reflexões a partir do caso do Murumuru. In: PLAZA, C. M. C.; DEL NERO, P. A. Proteção Jurídica para as Ciências da Vida: Propriedade Intelectual e Biotecnologia. São Paulo, p.26-58, 2012.

SACCARO JR, N. L. A regulamentação de acesso a recursos genéticos e repartição de benefícios: disputas dentro e fora do Brasil. Ambiente \& Sociedade, Campinas v.14, n.1 p.229244, 2011.

YUNES, R. A.; CECHINEL FILHO, V. In: YUNES, R. A.; CALIXTO, J.B. (Orgs.). Plantas Medicinais sob a Ótica da Química Medicinal Moderna. Chapecó: Argos, 2001. 